\title{
Complete maps of the aspect sensitivity of VHF atmospheric radar echoes
}

\author{
R. M. Worthington ${ }^{1}$, R. D. Palmer ${ }^{2}$, S. Fukao ${ }^{3}$ \\ ${ }^{1}$ Department of Physics, University of Wales, Aberystwyth, Wales, UK \\ ${ }^{2}$ Department of Electrical Engineering, Center for Electro-Optics, University of Nebraska, Lincoln, USA \\ ${ }^{3}$ Radio Atmospheric Science Center, Kyoto University, Kyoto, Japan
}

Received: 26 October 1998 / Accepted: 9 March 1999

\begin{abstract}
Using the MU radar at Shigaraki, Japan $\left(34.85^{\circ} \mathrm{N}, 136.10^{\circ} \mathrm{E}\right)$, we measure the power distribution pattern of VHF radar echoes from the mid-troposphere. The large number of radar beam-pointing directions (320) allows the mapping of echo power from $0^{\circ}$ to $40^{\circ}$ from zenith, and also the dependence on azimuth, which has not been achieved before at VHF wavelengths. The results show how vertical shear of the horizontal wind is associated with a definite skewing of the VHF echo power distribution, for beam angles as far as $30^{\circ}$ or more from zenith, so that aspect sensitivity cannot be assumed negligible at any beam-pointing angle that most existing VHF radars are able to use. Consequently, the use of VHF echo power to calculate intensity of atmospheric turbulence, which assumes only isotropic backscatter at large beam zenith angles, will sometimes not be valid.
\end{abstract}

Key words. Meteorology and atmospheric dynamics (middle atmosphere dynamics; turbulence; instruments and techniques)

\section{Introduction}

VHF radar wind-profilers are widely used worldwide, but no high-resolution measurements have been made showing the dependence of their backscattered power on the radar beam-pointing direction (i.e. as a function of both zenith and azimuth angles, from vertical to large zenith angles). VHF backscatter has long been known to be aspect-sensitive, the echo power decreasing as a radar beam is pointed away from zenith (Gage and Green 1978; Röttger and Liu, 1978; Fukao et al., 1979), and aspect sensitivity is usually much stronger in the stable stratosphere than in the troposphere. There has been uncertainty about the zenith angle beyond

Correspondence to: R. M. Worthington which aspect sensitivity is negligible, maybe $\approx 10^{\circ}$, or possibly as large as $18^{\circ}$ (Tsuda et al., 1997a). Recently, a dependence of echo power on azimuth angle has also been discovered (e.g. Tsuda et al., 1997b). This may be caused by gravity waves tilting the aspect-sensitive scatterers, first proposed by Gage et al. (1981), and further evidence of tilting caused by mountain waves is presented by Worthington (1999). VHF echo power patterns are also found to be skewed in regions of wind shear, as observed using the MST radar at Aberystwyth (Worthington and Thomas, 1996 (Sect. 4.2, 5), 1997) and the MU radar (Palmer et al., 1998; Worthington et al., 1999). An explanation for the results shown here, and those in earlier papers, may be that small-scale Kelvin-Helmholtz Instabilities (KHI) or steepening in regions of windshear are tilting the aspect-sensitive scatterers from horizontal (Worthington and Thomas, 1997, hereafter WT97). The wind shears (i.e. vertical shear of the horizontal wind) may be the large-scale shears above and below the jet stream maximum, or those caused by inertia-gravity waves, for example. Surprisingly, WT97 found that even fairly weak windshears (as measured by radar over height intervals of $300 \mathrm{~m}$ ) cause the echo power distribution to be skewed, and for zenith angles as large as $12^{\circ}$ (Fig. 6 of WT97), which is not consistent with the common assumption of isotropic echoes for VHF radar beams pointing $>10^{\circ}$ from zenith (e.g. Hocking and $\mathrm{Mu}, 1997)$.

Further investigations have usually been limited by technical restrictions on radar beam-pointing directions. For example, WT97 studied echo power imbalances between only two symmetric pairs of radar beams, which should have equal echo powers in the absence of tilting. This paper uses radar data with 320 beams (Fig. 1a), i.e. 5 groups of 64 beams, switching every inter-pulse-period between the beams in each 64-beam group (e.g. Palmer et al., 1998), and measuring all 5 groups in a cycle time of 5 min 20 s. Note in Fig. 1b-f that concentric rings of radar beams are used as much as possible, so that the measurement method has no bias to any particular azimuth. The data were recorded 2234 LT, 6 July 1998-0657 LT, 7 July 1998. The radar range resolution is $150 \mathrm{~m}$, from $9.00 \mathrm{~km}$ to $18.45 \mathrm{~km}$, e.g. the 


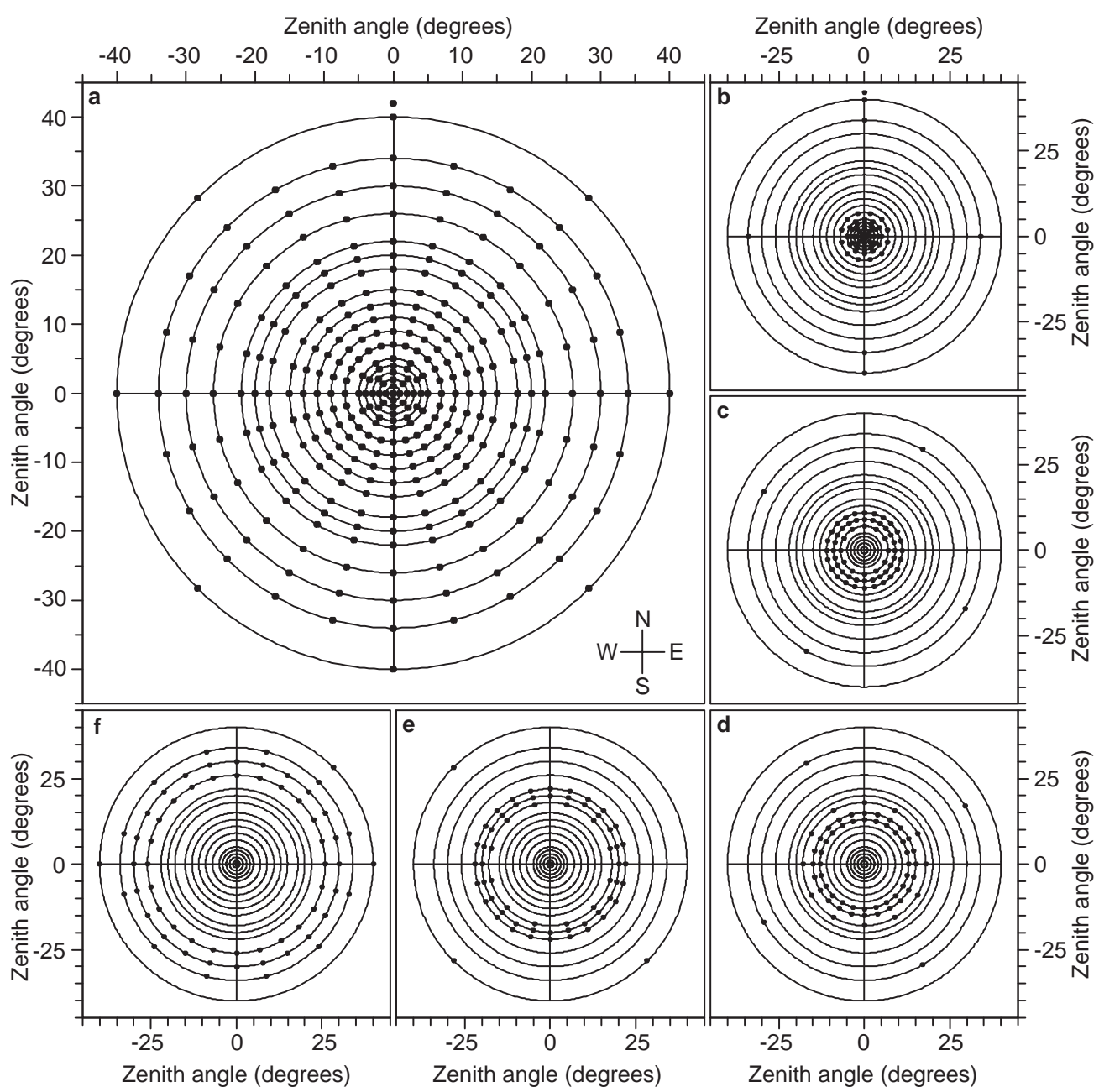

Fig. 1. Layout of the 320 radar beams, viewed from above; $a$ the complete pattern, b-f five subgroups of 64 beams each, used to build up the 320-beam pattern height coverage is $9.00-18.45 \mathrm{~km}$ for the vertical beam, and $6.89-14.13 \mathrm{~km}$ for the beams $40^{\circ}$ from zenith. Both cubic splining, and using the range gate nearest to the nominal height, were used to plot echo power maps; neither method introduces a bias to any particular azimuth. Furthermore, both methods provide similar results, so the second, simpler method is used. Because of weak signal-to-noise ratio (SNR) below the tropopause near $15 \mathrm{~km}$, only the region of good SNR below $10 \mathrm{~km}$ is studied here. Wind and wind shear vectors are plotted in Fig. 2a, b. The horizontal wind speed of $\sim 15 \mathrm{~m} \mathrm{~s}^{-1}$ (confirmed also by synoptic charts) is quite weak, and since the aliasing velocity is $15.7 \mathrm{~m} \mathrm{~s}^{-1}$, the wind component measured in any radar beam is not sufficient to cause aliasing problems. The wind shear in Fig. $2 b$ is quite weak with variable direction, except in the region marked by a box, near the completion of the experiment.

\section{High-resolution VHF echo power maps}

Figure 3a-d show four 313-beam maps of VHF echo power distribution, chosen to be during atmospheric conditions both with and without significant wind shear. Echo powers for each beam are averaged for $1 \mathrm{~h}$, and then interpolated. Correction is made for the slight loss of antenna gain due to a decrease in effective antenna aperture with increasing beam zenith angle. Consistent with Palmer et al. (1998), WT97, and Worthington et al. (1999), the echo power plots in regions of wind shear (Fig. 3a, b) are skewed and not centred on zenith, and this effect can, for the first time be seen to extend to very large angles from zenith, $30^{\circ}$ or greater. For example, the average echo power in the NE30 $0^{\circ}$ beam is about $4 \mathrm{~dB}$ higher than in the $\mathrm{SW} 30^{\circ}$ beam in Fig. 3a, b; even the quite weak shears of $10 \mathrm{~m} \mathrm{~s}^{-1} \mathrm{~km}^{-1}$ (Fig. 2b) are associated here with echo power imbalances at large beam zenith angles, as found by WT97. A $20^{\circ}$-reference-circle has been placed on the echo power maps, which emphasizes the aspect sensitivity at large zenith angles. Note that it is the azimuthal dependence of echo power, and not simply its decrease as the radar-beam zenith angle increases, that together imply aspect sensitivity. The tilting of a few aspect-sensitive scatterers a far as $20^{\circ}$ from horizontal is greater than can be explained by a gravity-wave spectrum model of Tsuda et al. (1997a), which predicts less echo power than they observe at zenith angles of $8-20^{\circ}$. However tilt angles as large as $20^{\circ}$ could occur in KHI (Fritts and Rastogi, 1985), within regions of large-scale wind shear. In contrast, Fig. 3c, d, without significant wind shear, show nearly circular 
a Horizontal wind vectors $(U, \mathrm{~V})$

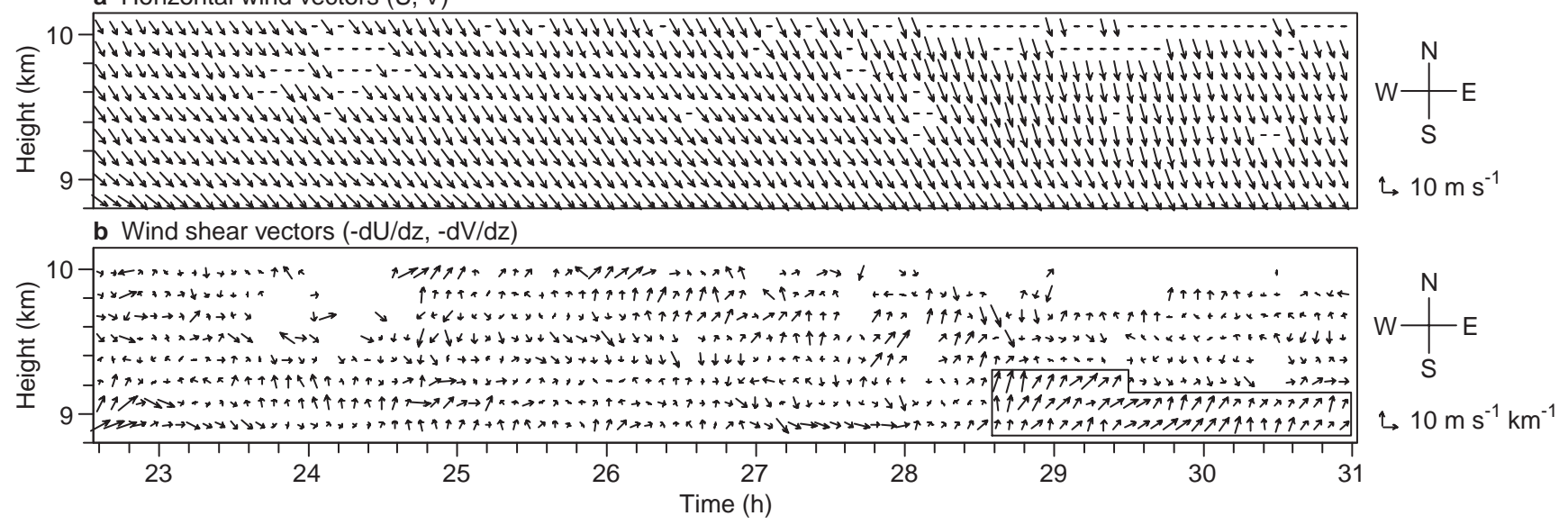

Fig. 2. a Height-time plot of horizontal wind vectors, 2234 LT, 6 July 1998 - 0657 LT, 7 July 1998. b Vectors showing the vertical shears of the zonal and meridional winds. The shear direction is extremely variable, except in the area marked by a box
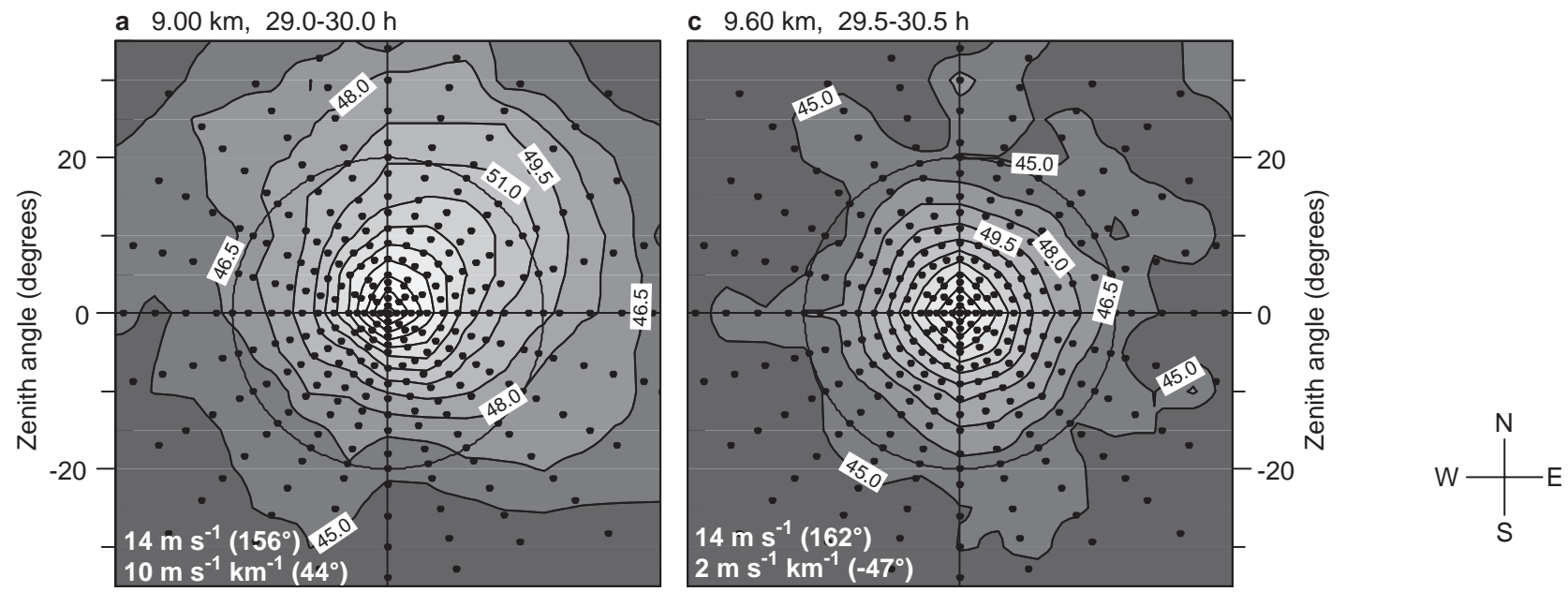

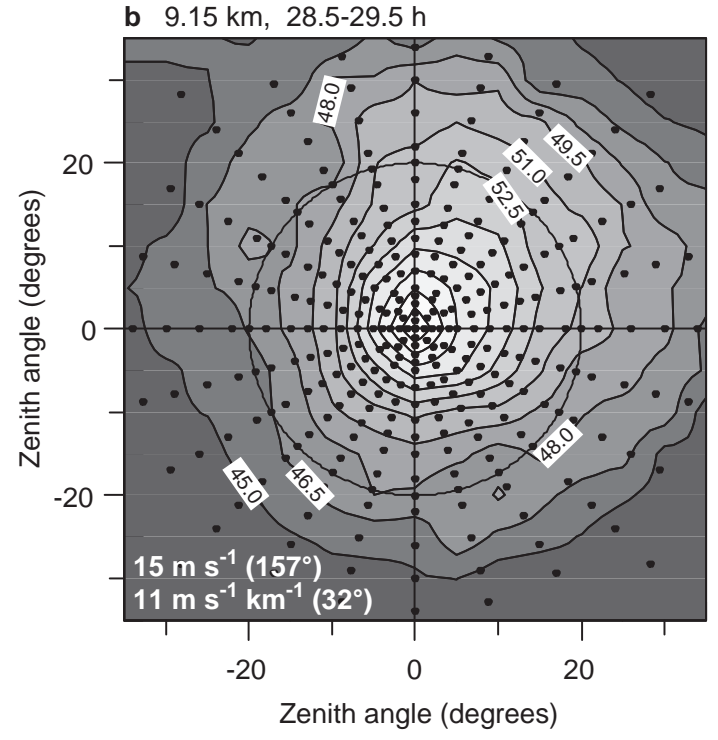

Fig. 3. Four typical maps of VHF echo power distribution patterns, averaged over 1-h time intervals, a and $\mathbf{b}$ are during atmospheric conditions of combined aspect sensitivity and windshear, $\mathbf{c}$ and $\mathbf{d}$ during conditions of aspect sensitivity but weak windshear. Dots mark the centres of the radar beam pointing directions (Fig. 1a). The echo power patterns in conditions of windshear (plots $a, b$ ) are

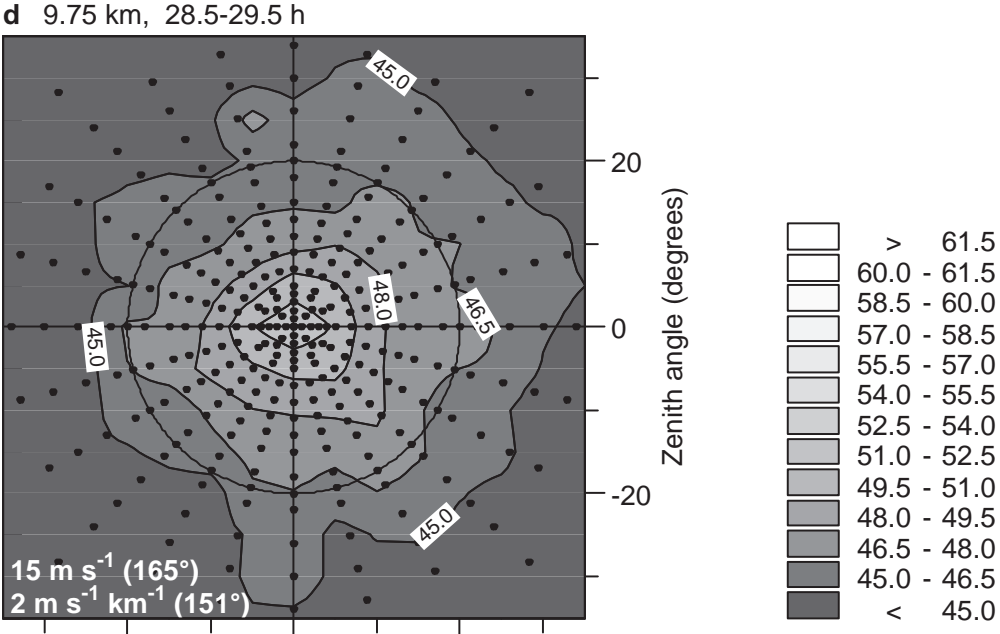

$-20$

Zenith angle (degrees) skewed in the direction of the windshear (Fig. 2b). A reference circle shows a zenith angle of $20^{\circ}$. The mean magnitude and direction of the horizontal wind speed and shear are printed for each power map. The shear is measured over a height interval of $300 \mathrm{~m}$, using the height gate above and below that of the echo power measurement 
echo-power contour lines centred on zenith. The azimuthal variation of sky noise does not appear to be significant, since the contours centred near zenith in Fig. 3d are observed at the same time, and only $600 \mathrm{~m}$ higher, than the skewed contours in Fig. 3b. Maps of the calculated noise level of the spectra (not shown) are almost flat, with variations of $<1.5 \mathrm{~dB}$ showing no relation to the skewed echo power distribution in Fig. 3a, b. Maps of the line-of-sight velocity are also plotted as a test for data reliability, and are consistent with a wind field horizontally uniform across the region spanned by the radar beams. Similarly, maps of the standard error show it is $<1-2 \mathrm{~dB}$ on each data point.

If VHF echoes from beam zenith angles as large as $30^{\circ}$ are not always isotropic, then turbulence intensity calculations based on the isotropic refractivity structure function $C_{\mathrm{n}}^{2}$ (Gage et al., 1980; Hocking and $\mathrm{Mu}, 1997$ ) will only be meaningful in (rare) atmospheric conditions of completely isotropic turbulence and/or zero wind shear, or if beams at $\approx 40^{\circ}$ or more from zenith can be used. In layers of strong wind shear and increased turbulence, Hooper and Thomas (1998, their Fig. 3) find a minimum of echo power, for beams pointed both vertically and as far as $12^{\circ}$ from zenith. After correction for the effect of stability on echo power, the resulting turbulence intensity profile (using the radar beam at e.g. $10^{\circ}$ or $12^{\circ}$ from zenith) should, however, show a maximum (Hocking and $\mathrm{Mu}, 1997$ ). Figure 3 suggests that vertical shear of horizontal wind, without necessarily causing any turbulence, can redistribute significant echo power from near-vertical to large zenith angles (WT97). An apparent increase of $C_{\mathrm{n}}^{2}$, caused by specular reflections, could be misinterpreted as an increase caused by more intense isotropic turbulence, and cause discrepancies in the calculated turbulence intensity profile.

\section{Conclusion}

Direct Doppler-beam-swinging measurements of VHF echo power, using 320 radar beams, show that aspectsensitivity cannot be assumed negligible even at $30^{\circ}$ from zenith, and may not be negligible at any beam zenith angle that most VHF radars are able to use. Consequently, one of the main assumptions in the use of VHF echo power to calculate turbulence intensity is sometimes not valid. Future high-resolution echo power maps could also be measured in the lower stratosphere, where there is often simultaneous strong aspect sensitivity and strong wind shear. Models of inertia-gravity wave instability (e.g. Lelong and Dunkerton, 1998) may be able to demonstrate the effect of fine-scale stable layers giving VHF echoes by Fresnel scatter, embedded within the larger-scale structure of inertia-gravity waves. Changes in VHF echo power patterns as the Richardson number $R i \rightarrow \frac{1}{4}$, e.g. in high-shear regions of inertia-gravity waves in the lower stratosphere, may be especially interesting.
Acknowledgements. R.D.P. was supported by the Division of Atmospheric Sciences of the National Science Foundation through grant ATM 94-02021. The MU radar belongs to and is operated by the Radio Atmospheric Science Center of Kyoto University. R.M.W. is grateful to Dr. T.S. Virdi for technical help with extracting data from Exabyte tape.

Topical Editor F. Vial thanks a referee for his help in evaluating this paper.

\section{References}

Fritts, D. C., and P. K. Rastogi, Convective and dynamical instabilities due to gravity wave motions in the lower and middle atmosphere: theory and observations. Radio Sci., 20, 1247-1277, 1985.

Fukao, S., T. Sato, S. Kato, R. M. Harper, R. F. Woodman, and W. E. Gordon, Mesospheric winds and waves over Jicamarca on May 23-24, 1974. J. Geophys. Res., 84, 4379-4386, 1979.

Gage, K. S., and J. L. Green, Evidence for specular reflection from monostatic VHF radar observations of the stratosphere. Radio Sci., 13, 991-1001, 1978.

Gage, K. S., J. L. Green, and T. E. VanZandt, Use of Doppler radar for the measurement of atmospheric turbulence parameters from the intensity of clear-air echoes. Radio Sci., 15, 407-416, 1980.

Gage, K. S., D. A. Carter, and W. L. Ecklund, The effect of gravity waves on specular echoes observed by the Poker Flat MST radar, Geophys. Res. Lett., 8, 599-602, 1981.

Hocking, W. K., and P. K. L. Mu, Upper and middle tropospheric kinetic energy dissipation rates from measurements of $\overline{C_{\mathrm{n}}^{2}}$ review of theories, in-situ investigations, and experimental studies using the Buckland Park atmospheric radar in Australia, J. Atmos. Sol. Terr. Phys., 59, 1779-1803, 1997.

Hooper, D. A., and L. Thomas, Complementary criteria for identifying regions of intense atmospheric turbulence using lower VHF radar, J. Atmos. Sol. Terr. Phys., 60, 49-61, 1998.

Lelong, M. P., and T. J. Dunkerton, Inertia-gravity wave breaking in three dimensions. Part I: convectively stable waves. J. Atmos. Sci., 55, 2473-2488, 1998.

Palmer, R. D., M. F. Larsen, S. Fukao, and M. Yamamoto, On the relationship between aspect sensitivity and spatial interferometric in-beam incidence angles. J. Atmos. Sol. Terr. Phys., 60, 37-48, 1998.

Röttger, J., and C. H. Liu, Partial reflection and scattering of VHF radar signals from the clear atmosphere. Geophys. Res. Lett., 5, 357-360, 1978.

Tsuda, T., T. E. VanZandt, and H. Saito, Zenith-angle dependence of VHF specular reflection echoes in the lower atmosphere, J. Atmos. Sol. Terr. Phys., 59, 761-775, 1997 a.

Tsuda, T., W. E. Gordon, and H. Saito, Azimuth angle variations of specular reflection echoes in the lower atmosphere observed with the MU radar. J. Atmos. Sol. Terr. Phys., 59, 777-784, 1997b.

Worthington, R. M., Calculating the azimuth of mountain waves, using the effect of tilted fine-scale stable layers on VHF radar echoes, Ann. Geophys., 17, 257-272, 1999.

Worthington, R. M., and L. Thomas, The measurement of gravity wave momentum flux in the lower atmosphere using VHF radar. Radio Sci., 31, 1501-1517, 1996.

Worthington, R. M., and L. Thomas, Long-period unstable gravitywaves and associated VHF radar echoes, Ann. Geophys., 15, 813-822, 1997.

Worthington, R. M., R. D. Palmer, and S. Fukao, An investigation of tilted aspect-sensitive scatters in the lower atmosphere using the MU and Aberystwyth VHF radars, Radio Sci., 34, 413-426, 1999. 